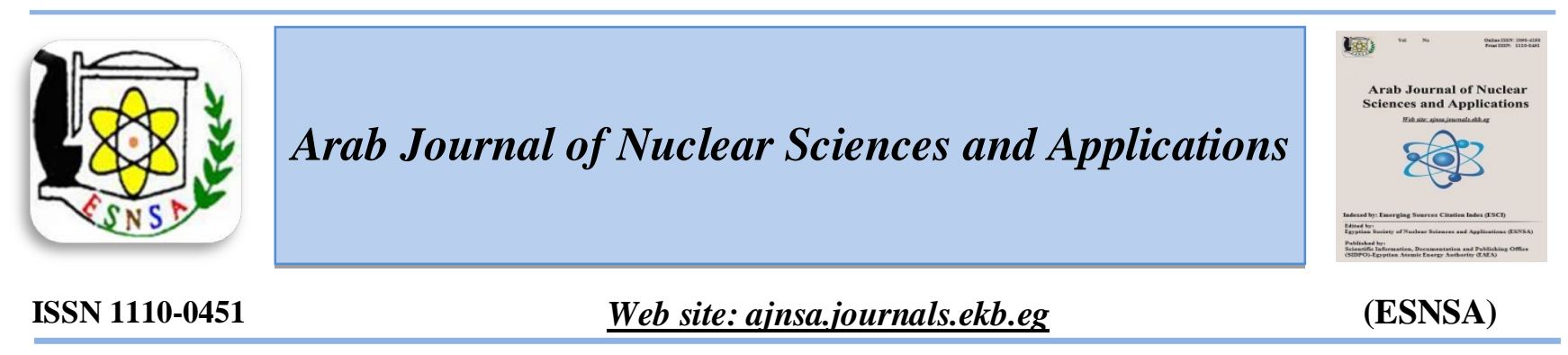

\title{
Evaluation of the Annual Effective Dose of the NORM Decontamination Workers During Cleaning the Oil and Gas Equipment
}

\author{
O. S. Desouky ${ }^{(1)}$ and T. M. Morsi ${ }^{(2)}$ \\ ${ }^{1}$ Radiation Physics Department, National Center for Radiation Research and Technology, Egyptian Atomic \\ Energy Authority, Cairo, Egypt \\ ${ }^{2}$ Radiation Protection Department, Nuclear Research Center, Egyptian Atomic Energy Authority, Cairo, Egypt \\ Egypt
}

\begin{abstract}
Received $14^{\text {th }}$ Jan 2018 Oil and gas production processing operations have been known to produce a large amount of naturally Accepted $1^{\text {st }}$ March
2018 means that TE-NORM (technologically-enhanced naturally occurring radioactive materials) wastes from the oil \& gas industry may generate radiation exposure levels, which require attention and continuous monitoring during NORM decontamination of oil and gas equipment. This exposure is mostly caused by external and internal radiation coming from the ${ }^{226} \mathrm{Ra} \&{ }^{228} \mathrm{Ra}(\mathrm{U}-238$ and Th -232 series) radionuclides and their progenies. This study focuses on follow up of the annual effective dose for workers during decontaminating naturally occurring radioactive materials (NORM) of oil and gas equipment. The external effective dose was evaluated using thermoluminescence detector (TLD). The obtained data showed that the range of the annual dose was from 1.07 to $1.78 \mathrm{mSv}$ and the average dose of the ten workers under investigation was $1.4 \pm 0.24 \mathrm{mSv}$. The average dose is about $7 \%$ of the occupational annual dose limit. It is concluded that protective measures against external and internal contamination helped in the protection of the workers against NORM hazards).
\end{abstract}

\section{Introduction}

In onshore and offshore oil and gas production activities, a mixture of TE-NORMs, oil, gas, water, sludge, and sand is brought to the surface via drilled wells through down-hole completion and production equipment [1]. The global petroleum industry generates millions of tons of TE-NORM wastes annually including produced water, scales, sludge, and contaminated equipment; which are disposed of either above ground or underground. Accordingly, there is a growing concern as to how these massive volumes of daily produced TENORMs can be managed and disposed of in a safe manner [2].
In many oil and gas fields, the build-up of scale in pipes and vessels constitutes a significant radiological hazard. Typically, the scale is a result of mineral impurities that build-up because of the injection of incompatible water into the well, evaporation in gaseous wells, pressure changes and/or temperature drops. The material is either a barium/strontium sulphate $\left(\mathrm{Ba}(\mathrm{Sr})-\mathrm{SO}_{4}\right)$ or calcium carbonate $\left(\mathrm{CaCO}_{3}\right)$ precipitate. Radium isotopes accompany barium and strontium as well as calcium in water/oil mixtures and co-precipitate. The main radiation protection problems associated with the scales are irradiation exposure of staff in areas where the scale is deposited and internal contamination by those removing the scale $[3,4,5]$.

Corresponding author: omardesouky@gmail.com

DOI: 10.21608/ajnsa.2018. 2644.1041

(c) Scientific Information, Documentation and Publishing Office (SIDPO)-EAEA 
Radium-containing waste is generated during maintenance activities of oil and gas facility components such as tubing, vessels and storage tanks. Sludge comprises hydrocarbons, heavy metals, natural radionuclides, sediments and to a lesser extent, scales and corrosion products. Scales are sulphates or carbonates of barium, strontium, calcium, magnesium and radium. Some scalecontaminated components such as pumps and valves cannot be cleaned easily. The use of scale inhibitors reduces the formation of scale deposits. Thus, most radium will remain in the liquid streams in the diluted form [6].

Uncontrolled activities associated with enhanced levels of NORM can contaminate the environment and pose risks to human health. These risks can be alleviated by the adoption of controls to identify where NORM is present, and by the control of NORM-contaminated equipment and waste while protecting workers. The general principles of radiation protection are primarily implemented by means of good protective measures at the workplaces. Hence, exposure control and adequate dosimetry are the most critical components of a health and safety program [7].

Part of a successful NORM management strategy is the ability to decontaminate equipment, which has become contaminated with Naturally Occurring Radioactive Material. The removal of relatively insoluble NORM scale, adhering to equipment surfaces, requires aggressive agitation of the surface to remove it. The control of NORM contamination removed from contaminated equipment and the protection of workers during the decontamination process is achieved primarily by engineering controls, that must be supported by administrative procedures and personal protective equipment (PPE)[8].

NORM contaminated equipment cannot be released for sale or re-use as it has enhanced levels of radioactivity, which can lead to radiation exposure of workers, the general public and the environment, if not managed appropriately. The goals of the decontamination process are the safe removal of NORM from the equipment, delivering insignificant radiation exposure to the workers, and without impacting the environment by spreading NORM contamination. The main radiation protection problems associated with the
NORM scales are irradiation of staff in areas where scales are deposited and internal contamination by those removing the scales.

The aim of this study is to estimate the potential radiological dose to workers during decontamination for the naturally occurring radioactive materials (NORM)). The radiation workers under investigation were examined externally using thermoluminescence detectors (TLD) for assessing the external dose during one working year.

\section{Materials and Methods}

Decontamination facility

NORM decontamination closed facility was used to ensure the safety of workers and restricted the spread of NORM contamination. High pressure air jetting (HPAJ) and sand abrasive were selected as the method of decontamination as this would effectively remove the NORM contamination without damaging the component. Adequate space was provided to ensure that NORM-contaminated equipment could be handled and transported safely from its storage location to the NORMdecontamination facility and then to postdecontamination storage racks.

Within the controlled area, all workers wear the following personal protective equipment (PPE) to prevent the internal contamination, standard dust mask, disposable coveralls, industrial gloves and safety boots. After use, the PPE is removed and surveyed to determine if it had become contaminated with NORM. If it found to be free from NORM contamination, the PPE could be reused. All equipment is cleaned and decontaminated to natural background radiation level before reuse. The NORM waste is collected and placed in highdensity polyethylene (HDPE) drums that are sealed and is temporarily stored according to NORM management strategy pending final disposal in an approved NORM disposal facility.

\section{NORM survey instrumentation}

A Ludlum Measurements, model 3-97 radiation survey meter was used to perform equipment survey. The internal scintillation detector for this survey meter is ideal for detecting low intensity gamma photon radiation. This model 3-97 survey meter was last calibrated on November 24, 2016 at the National Institute for Standers (NIS). The meter is equipped with an external model 44-9 
"pancake" Geiger Mueller detector. The primary role of this detector is to survey surfaces for evidence of radioactive contamination, from alpha, beta and gamma emitting radioactive isotopes. Since no evidence of NORM accumulation was detected, there was no requirement for the model 44-9 "pancake" Mueller detector to be used.

\section{NORM survey procedure}

Prior to the start of the NORM survey, an environmental radiation (background) intensity measurement was made for determining the incremental radiation dose. Ambient background radiation measurements were made on contact with the ground away from the contaminated equipment. A "background" radiation intensity is from 0.08 to $0.12 \mu \mathrm{Sv} / \mathrm{h}$, and the NORM action level is double the background. Background radiation is a term used to describe radiation that occurs naturally in the environment. Background radiation consists of cosmic radiation from outer space, radioactive elements in rocks and soil, and radiation from radon and its decay products in the air that we breathe.

\section{External dose measurement}

The number of decontaminated workers is ten. The workers were provided with TLD to estimate the external effective dose before starting the job; the TLDs were evaluated every three months. The evaluation of the TLDs was carried at the National Institute for Standards using Harshaw reader. The TLDs were calibrated using Cs-137 source and UNIDOS meter (PTW, Freiburg). The combined uncertainty value is $1.75 \%$ for secondary standard dosimetry. The calibration method is performed according to the IAEA safety reports.

\section{Gamma ray measurement}

10 samples of NORM were collected after decontamination the equipment. For measuring radioactivity concentration, $0.5 \mathrm{~kg}$ of NORM sample packed in a plastic container, sealed and stored for 4 weeks to establish the secular equilibrium between the natural radionuclides and their respective progenies. The gamma-ray measurements for the NORM samples were carried out using High Purity Germanium detectors with the relative efficiency of $25 \%$, the correlation between energy to channel number was 0.5 $\mathrm{keV} / \mathrm{channel}$. The gamma-ray spectrum analyzed using a software program (Genie 2000) which calculates the activity concentration of the samples. The measuring counting time was 7200 second. The natural background radiation subtracted from the accumulated spectrum.

High purity germanium detector was calibrated using mixed-gamma sources in order to get quantitatively and qualitatively estimation of energies emitted from radionuclides by using its spectra. Efficiency calibration was determined using multi gamma standard source such as ${ }^{109} \mathrm{Cd}$, ${ }^{57} \mathrm{Co},{ }^{139} \mathrm{Ce},{ }^{113} \mathrm{Sn},{ }^{137} \mathrm{Cs},{ }^{88} \mathrm{Y}$ and ${ }^{60} \mathrm{Co}$ with total activity of $5 \mu \mathrm{Ci}$. The efficiency of a counter to gamma radiation emitted from a source is defined by $\mathrm{E}=\mathrm{N}_{0} / \mathrm{N}_{\gamma}$, where $\mathrm{N}_{\mathrm{o}}$ is the number of count rates observed and $\mathrm{N}_{\gamma}$ is the number of gamma photons emitted by a source. Figure (1) shows the efficiency calibration curve for HPGe. The counting efficiency and the statistical accuracy of measurements depend on sample geometry and the energy of incident photons.

\section{Results and Discussion}

During the production process, NORM flows with oil, gas and water mixture and accumulates in scale, sludge and scrapings. It can also form a thin film on the interior surfaces of gas processing equipment and vessels as the result of radon gas decay. The level of NORM accumulation can vary substantially from one facility to another (radioactive materials are not necessarily present in soil at every well site) depending on geological formation, operational and other factors.

The NORM nuclides of primary concern in oil production are ${ }^{226} \mathrm{Ra}$ and ${ }^{228} \mathrm{R}$. These decay into various radioactive progeny, before becoming stable lead. ${ }^{226} \mathrm{Ra}$ belongs to the ${ }^{238} \mathrm{U}$ decay series and ${ }^{228}$ Rato the ${ }^{232} \mathrm{Th}$ decay series. The level of reported radioactivity can vary significantly, depending on the radioactivity of the reservoir rock and the salinity of the water coproduced from the well. The higher the salinity the more NORM is likely to be mobilized. Since salinity often increases with the age of a well, old wells tend to exhibit higher NORM levels than younger ones.

The specific activity concentrations of ${ }^{226} \mathrm{Ra}$ and ${ }^{228} \mathrm{Ra}$ in hard scale ranged from $0.1 \mathrm{~Bq} / \mathrm{g}$ to $15000 \mathrm{~Bq} / \mathrm{g}$ and 0.05 to $2800 \mathrm{~Bq} / \mathrm{g}$, and in case of the sludge, it ranged from 0.05 to $800 \mathrm{~Bq} / \mathrm{g}$ and 0.5 to $50 \mathrm{~Bq} / \mathrm{g}$ respectively (IAEA, 2003). 


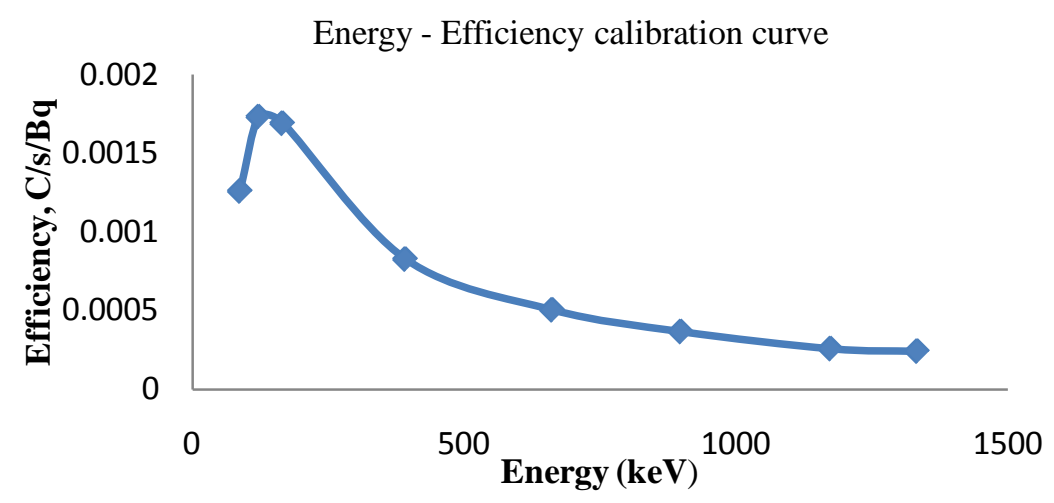

Figure (1) typical calibration curve for HPGe detector installed at NRC, EAEA

Generally, the activity concentrations of radium isotopes are lower in sludge than in scales. The opposite applies to ${ }^{210} \mathrm{~Pb}$, which usually has a relatively low concentration in hard scales but may reach a concentration of more than $1000 \mathrm{~Bq} / \mathrm{g}$ in lead deposits and sludge. It is identified at a level of exemption/removal of $1 \mathrm{~Bq} / \mathrm{g}$ for radionuclides of the series of ${ }^{238} \mathrm{U}$ and ${ }^{232} \mathrm{Th}$ (in secular equilibrium) and $10 \mathrm{~Bq} / \mathrm{g}$ for the ${ }^{40} \mathrm{~K}$ (with the exception of NORM processing residues that are used in building materials (IAEA, 2003) [9].

Table (1) and Figure (2) illustrate the values of specific activity concentrations for samples under investigations. From the obtained results, it is found that the specific activity concentration of ${ }^{238} \mathrm{U}$ ranged from 773 to $3409 \mathrm{~Bq} / \mathrm{kg}$ with an average value of $1723 \mathrm{~Bq} / \mathrm{kg}$. The activity concentration of ${ }^{232} \mathrm{Th}$ ranged from 239 to 1595

$\mathrm{Bq} / \mathrm{kg}$ with an average value of $667 \mathrm{~Bq} / \mathrm{kg}$. The activity concentration of ${ }^{40} \mathrm{~K}$ ranged from 171 to $437 \mathrm{~Bq} / \mathrm{kg}$ with an average value of $315 \mathrm{~Bq} / \mathrm{kg}$.

It is obvious from the activity concentrations measurement of the NORM samples from the contaminated equipment that the concentration of 226Ra is higher than that of ${ }^{228} \mathrm{Ra}$.

The deposition of contaminated scales and sludge in pipes and vessels may produce significant dose rates inside and outside these components. Shortlived progeny of the radium isotopes, in particular, ${ }^{226} \mathrm{Ra}$ at energy $186.2 \mathrm{keV}$, emit gamma radiation capable of penetrating the walls of these components.
Table (1): specific activity concentrations of ${ }^{238} \mathrm{U},{ }^{232} \mathrm{Th}$

\begin{tabular}{|c|c|c|c|}
\hline & $\begin{array}{c}\mathbf{U}-\mathbf{2 3 8} \\
(\mathbf{B q} / \mathbf{K g}) \mathbf{)}))\end{array}$ & $\begin{array}{c}\mathbf{T h}-\mathbf{2 3 2} \\
\mathbf{( B q / K g})\end{array}$ & $\begin{array}{c}\mathbf{K}-\mathbf{4 0} \\
\mathbf{( B q} / \mathbf{K g})\end{array}$ \\
\hline & 1514 & 627 & 298 \\
\hline & 1367 & 449 & 204 \\
\hline & 2075 & 606 & 732 \\
\hline & 852 & 267 & 425 \\
\hline & 2156 & 862 & 171 \\
\hline & 965 & 239 & 267 \\
\hline & 2117 & 1046 & 206 \\
\hline & 2001 & 700 & 212 \\
\hline & 773 & 279 & 437 \\
\hline & 3409 & 1595 & 202 \\
\hline Average & 1722.9 & 667 & 315.4 \\
\hline SD & 802.263 & 420.385 & 173.775 \\
\hline
\end{tabular}

Moreover, the high-energy photon emitted by ${ }^{208} \mathrm{Tl}$ at energy $583 \mathrm{keV}$ (one of the progenies of ${ }^{232} \mathrm{Th}$ ) can contribute significantly to the dose rate on outside surfaces when the scale has been accumulating over several months. The dose rates depend on the amount and activity concentrations of radionuclides present inside and the shielding provided by pipe or vessel walls.

Maximum dose rates are usually up to a few $\mu \mathrm{Sv} / \mathrm{h}$. In exceptional cases, dose rates measured directly on the outside surfaces of production equipment have reached several hundred $\mu \mathrm{Sv} / \mathrm{h}$, which is about 1000 times greater than normal background values due to cosmic and terrestrial radiation. External exposure can be restricted by maximizing the distance and minimizing the time during exposure to, the components involved. In practice, restrictions on access and occupancy time are found to be effective in limiting annual doses to low values. [10]. 


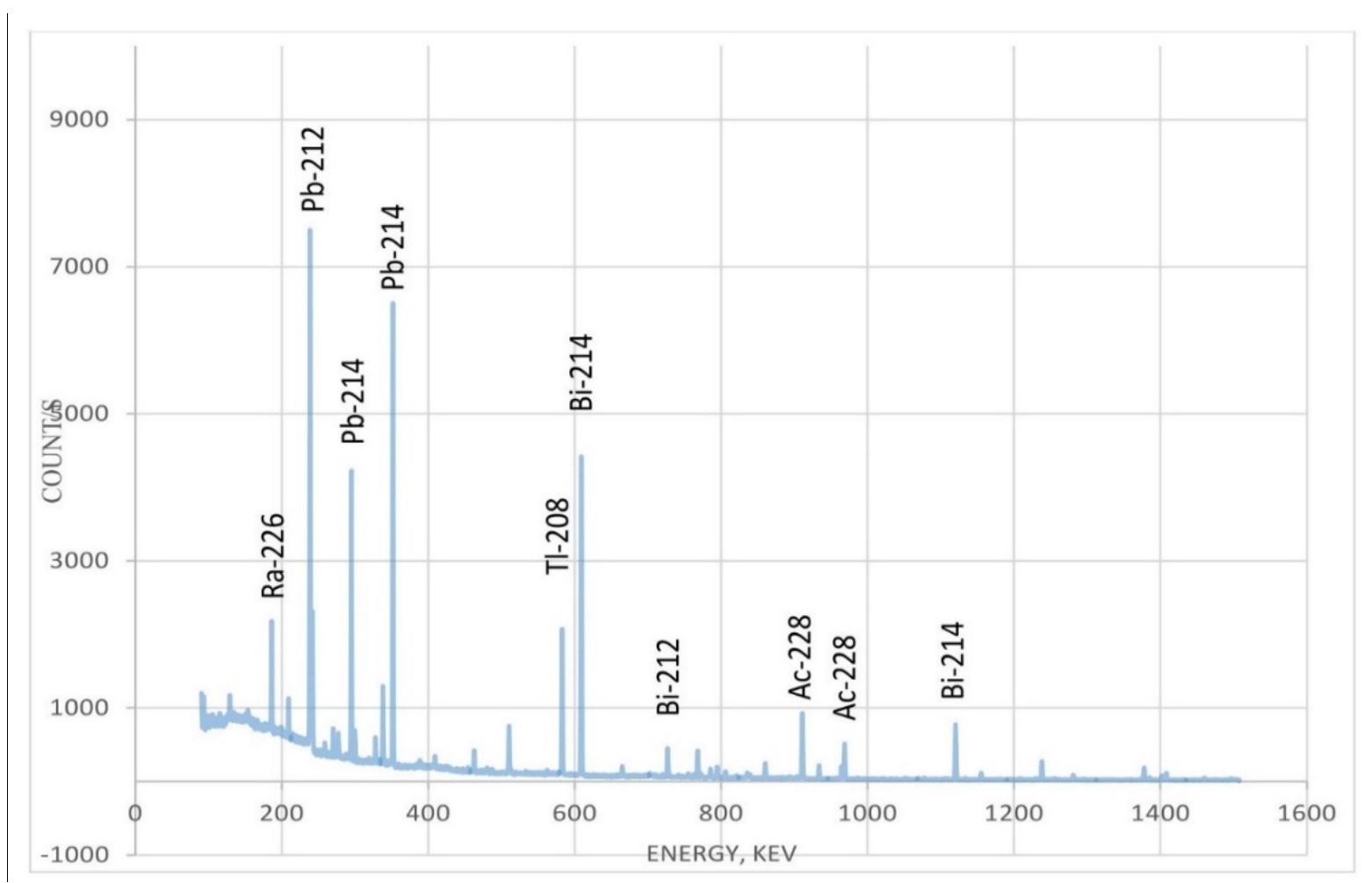

Figure (2) Typical gamma ray spectrum for NORM sample

Decontamination of NORM-contaminated equipment was carried out in a controlled manner to ensure workers protection, prevent the spread of NORM contamination, and to minimize the waste arising from the decontamination process. Simple mechanical/abrasive high-pressure air and water jetting (HAWJ) in conjunction with other mechanical/abrasive methods has been successfully used.

Table (2) shows the number of the facilities and the external radiation level. It was shown that the radiation level varied from facility to another. The highest radiation level observed for the motor of the ESP, which ranged from 0.6 to $55 \mu \mathrm{Sv} / \mathrm{h}$. The decontamination of this equipment was carried by the mechanical abrasive method to eliminate the NORM scale before re-using this equipment. Decontamination of NORM-contaminated equipment such as pipelines, vessels, pumps, were undertaken in a controlled manner to ensure worker protection, prevent the spread of NORM contamination, and to minimize the waste arising from the decontamination process.
Table (2): Number of decontaminated oil equipment and the external radiation level

\begin{tabular}{|l|l|l|}
\hline Facility & No & $\begin{array}{l}\text { External radiation } \\
\text { level }(\boldsymbol{\mu S v} / \mathbf{h})\end{array}$ \\
\hline Motor Seal & 40 & $0.56-5.29$ \\
\hline Motor & 45 & $0.62-55$ \\
\hline Pump Intakes & 30 & $0.8-16.25$ \\
\hline ESP Pump & 5 & $1.25-8.2$ \\
\hline Pipeline & 1000 & $0.8-45$ \\
\hline Separators & 2 & $5-30$ \\
\hline
\end{tabular}

Workers entering NORM-contaminated vessels or conducting decontamination work on NORM contaminated equipment are trained, qualified and certified in the associated hazards. All NORM operations are planned and organized. All hazards and precautions are evaluated before the beginning of the operations. Appropriate PPE must be worn and should consist of Tyvek, coveralls, gloves, Half-face respirators with HEPA cartridges or Quarter-face HEPA disposable respirators. Eating, drinking, and smoking prohibited in a radioactive area, or radioactive storage area when working with NORM. The time spent in NORM contaminated work-areas is optimized by 
calculating the allowable time spent in the controlled area. In addition, workers wear a personal dosimeter (TLD) during their time on the job.

Personnel wash up thoroughly after working with contaminated equipment, and before eating, drinking and at the end of the workday. Workers must be checked of any contamination with NORM before leaving the work area. The contaminated PPE were collected and stored in HDPE drums in the NORM yard. All the procedures are under the supervision of the radiation protection officer. period. The dose is measured every three months. The effective dose ranged from 1.07 to $1.78 \mathrm{mSv} / \mathrm{y}$ and the average of the ten workers was $1.4- \pm 0.24$ $\mathrm{mSv}$. It is obvious that the maximum dose of $1.78 \mathrm{mSv} / \mathrm{y}$ is nearly double the recommended annual dose of the public. Utilization of good protective measures against external and internal contamination was usefully in protecting decontamination workers against NORM hazards. The effective dose ranged from 5.35 to $8.9 \%$ of the occupational annual dose limit (20 mSv), while the average was $7 \%$ [11].

Table (3) and Figure (3) show the measured effective dose for ten workers over a one-year

Table (3): External effective dose of the decontaminated workers

\begin{tabular}{|c|c|c|c|c|c|}
\hline Workers & Q1 & Q2 & Q3 & Q4 & $\begin{array}{c}\text { Annual Effective dose } \\
\text { (mSv) }\end{array}$ \\
\hline W1 & 0.56 & 0.57 & 0.40 & 0.20 & 1.73 \\
\hline W2 & 0.41 & 0.61 & 0.53 & 0.23 & 1.78 \\
\hline W3 & 0.30 & 0.43 & 0.25 & 0.32 & 1.30 \\
\hline W4 & 0.14 & 0.70 & 0.23 & 0.35 & 1.42 \\
\hline W5 & 0.25 & 0.55 & 0.26 & 0.46 & 1.52 \\
\hline W6 & 0.19 & 0.55 & 0.15 & 0.29 & 1.18 \\
\hline W7 & 0.43 & 0.56 & 0.32 & 0.27 & 1.58 \\
\hline W8 & 0.17 & 0.28 & 0.36 & 0.34 & 1.15 \\
\hline W9 & 0.44 & 0.19 & 0.23 & 0.21 & 1.07 \\
\hline W10 & 0.58 & 0.33 & 0.15 & 0.30 & 1.36 \\
\hline Average & $\mathbf{0 . 3 4 7}$ & $\mathbf{0 . 4 7 7}$ & $\mathbf{0 . 2 8 8}$ & $\mathbf{0 . 2 9 7}$ & $\mathbf{1 . 4 0 9}$ \\
\hline SD & $\mathbf{0 . 1 5 9 7 2 5}$ & $\mathbf{0 . 1 6 2 8 2 6}$ & $\mathbf{0 . 1 1 7 5 4 9}$ & $\mathbf{0 . 0 7 7 4 6 7}$ & $\mathbf{0 . 2 4 2 9 2}$ \\
\hline
\end{tabular}

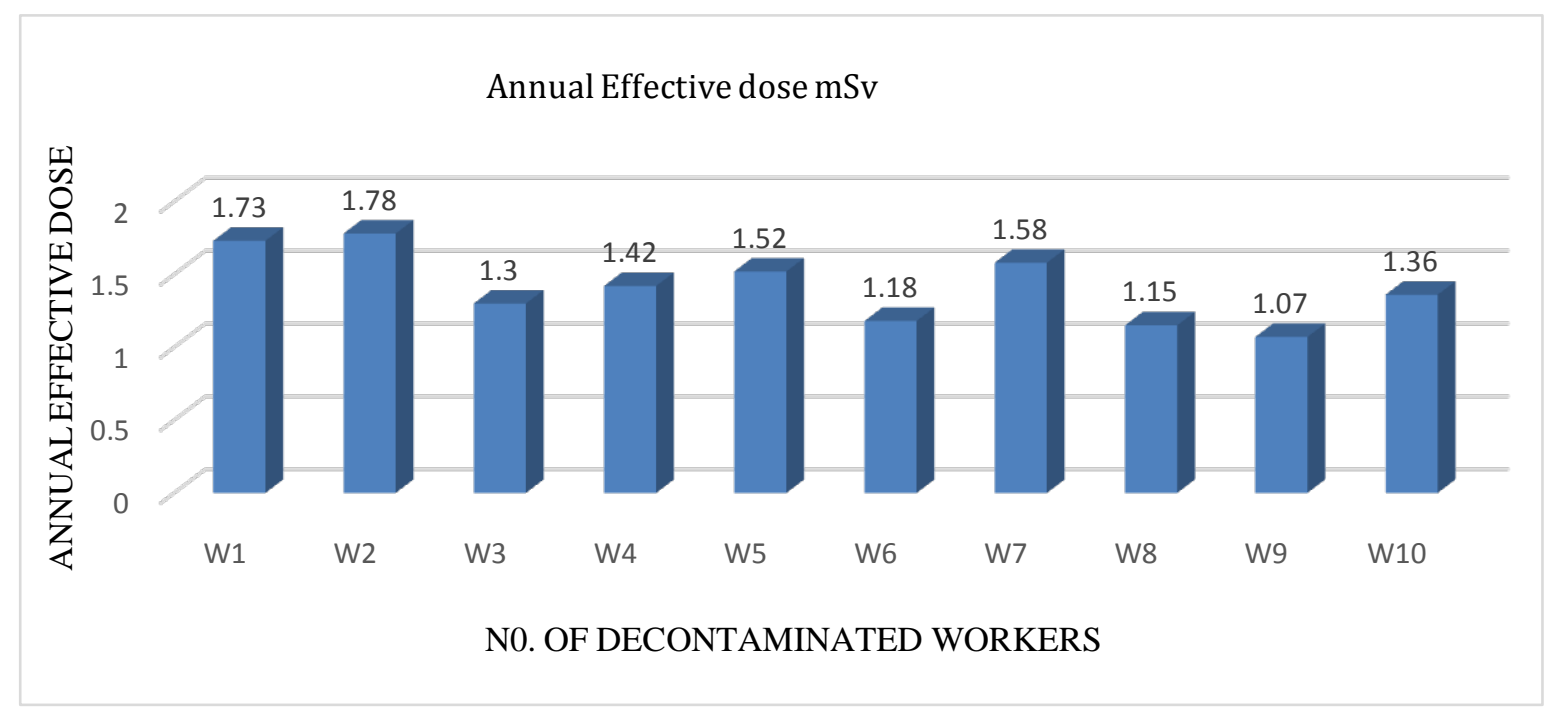

Figure (3) the annual effective dose for the decontamination workers 


\section{Conclusion}

It is recommended that special attention should be given to NORM decontamination workers in order to control factors affecting their exposure to radiation. Specifically, they should not be allowed to enter into the tanks to remove oil residues and scale if good ventilation conditions are not provided. Besides, all cleaning operations that require scraping or similar procedures for scale removal must be performed in wet conditions, in order to minimize the inhalation or ingestion of radioactive dust. Using protective masks is also required during all cleaning operations. The results support the setting of a national screening for exposure levels to NORM in different activities, and developing national control regulation dealing with NORM industries.

\section{References}

1. AL Nabhani, K., Khan, F., Yang, M. "Management of TENORMs produced during oil and gas operation"; Journal of Loss Prevention in the Process Industries; V. 47, PP. 161-168, (2017).

2. AL Nabhani, K., Khan, F., Yang, M., "Scenariobased risk assessment of TENORM waste disposal options in oil and gas industry"; Journal of Loss Prevention in the Process Industries;_V. 40, PP. 5566, (March 2016).

3. IAEA; "Extent of Environmental Contamination by Naturally Occurring Radioactive Material (NORM) and Technological Options for Mitigation”, Technical Reports Series N0. 419,_(2003).

4. Hamlat, M.S, Djeffal S, Kadi H.; “Assessment of radiation exposures from naturally occurring radioactive materials in the oil and gas industry"; Applied Radiation and Isotopes; V.55, Issue 1, PP. 141-146, (July 2001).

5. American Petroleum Institute (API); "Bulletin on Management of Naturally Occurring Radioactive Materials (NORM) in Oil and Gas Production” API Bulletin E2 (1992).

6. Gazineu MHP, de Araujo AA, Brandao YB, Hazin CA and Godoy JM; "Radioactivity concentration in liquid and solid phases of scale and sludge generated in the petroleum industry"; Journal of Environmental Radioactivity, V. 81, Issue 1, PP. 47-54 (2005).

7. International Association of Oil \& Gas Producers (OGP); "Guidelines for the management of Naturally Occurring Radioactive Material (NORM) in the oil \& gas industry”, Report No. 412, (September 2008).

8. Cowie, M., Mously, K., Fageeha, O., Nassar, R. "NORM Management in the oil and gas industry", Annals of the ICRP; V. 41, PP. 318-331, (2012).
9. IAEA; "Radiation Protection and the Management of Radioactive Waste in the Oil and Gas Industry", Safety Report Series N0.34, (2003).

10. IAEA; "Radiation Protection and the Management of Radioactive Waste in the Oil and Gas Industry", Training Course Series N0.40, (2010).

11. United Nations Scientific Committee On The Effects Of Atomic Radiation, Sources and Effects of Ionizing Radiation, UNSCEAR 2000 Report to the General Assembly, United Nations, New York, (2000). 